\title{
Pulmonary Distribution and Efficacy of Exogenous Surfactant in Lung-Lavaged Rabbits Are Influenced by the Instillation Technique
}

\author{
HUGO SEGERER. WARRY VAN GELDER, FRANZ W. M. ANGENENT. \\ LEON J. P. M. VAN WOERKENS, TORE CURSTEDT, MICHAEL OBLADEN, AND \\ BURKHARD LACHMANN
}

\author{
Departments of Anaesthesiology' [B.L., H.S.J. Chemical Pathology / W.y.G.J. Experimental Cardiolog. \\ [L.J.P.M.r.W.], and the Central Isotope Laboratory [F.W.M.A.J, Erasmus University, Rotterdam. \\ The Netherlands; the Department of Clinical Chemistry: Karolinska Institutet at Danderid Hospital. \\ Stockholm. Sw'eden [T.C.J: and the Department of Neonatology, Children's Hospital. \\ UniversitätsKlinikum Rudolf Virchow. Free University, Berlin, Germany /H.S., M.O./
}

\begin{abstract}
Surfactant bolus instillation has been reported to cause changes in arterial blood pressure (BP) and cerebral blood flow velocities which may increase the risk of intraventricular haemorrhage. To avoid these effects, slow tracheal infusion was evaluated as a possible alternative method of surfactant administration. Saline lung lavages were performed in 13 anesthetized and artificially ventilated adult rabbits to produce respiratory distress syndrome. Curosurf (CS, $200 \mathrm{mg} / \mathrm{kg}$ ) labeled with ${ }^{14} \mathrm{C}$-dipalmitoyl-phosphatidylcholine (-DPPC) and/or red microspheres (RMS) was instilled into the trachea either as a single bolus $(n=8)$ or by infusion during $45 \mathrm{~min}$ via a side-channel within the wall of the tracheal tube $(n=5)$. An arterial cannula was placed for monitoring of blood gases and BP. To determine surfactant distribution, the lungs were cut into 60-70 pieces and radioactivity and/or the number of RMS were measured in each piece. The distribution of RMS was closely related to the distribution of ${ }^{14} \mathrm{C}$-DPPC $(r=0.96)$. Bolus instillation of CS led to a prompt and sustained increase in $\mathrm{PaO}_{2}$ (from $<10.5$ to $>40$ $\mathbf{k P a}$ within $2 \mathrm{~min}$ ), a transient decrease in $\mathrm{BP}$, and a reasonably homogeneous pulmonary surfactant distribution. Tracheal infusion of $\mathrm{CS}$ changed neither $\mathrm{BP}$ nor $\mathrm{PaO}_{2}$ during the observation period of $60 \mathrm{~min}$. The pulmonary distribution of CS was extremely uneven after infusion. The distribution of exogenous surfactant and its effects on gas exchange are influenced by the instillation method. An inadequate instillation technique may add to the causes of "poor response" after surfactant replacement. (Pediatr Res 34: 490-494, 1993)
\end{abstract}

Abbreviations

CS, Curosurf

PIP, peak inspiratory pressure

PEEP, positive end-expiratory pressure

$\mathrm{PaO}_{2}$, arterial oxygen tension

$\mathrm{PaCO}_{2}$, arterial carbon dioxide tension

RMS, red microsphere

DPPC, dipalmitoyl-phosphatidylcholine

BP, blood pressure

Received November 9, 1992; accepted May 6, 1993

Correspondence: Dr. H. Segerer, Department of Neonatology, Children's Hospital, Universitätsklinikum Rudolf Virchow. Heubnerweg 6. D-14059 Berlin, Germany.

Supported by a grant from the Deutsche Forschungsgemeinschaft, Ob 43/6-1 (H.S., M.O.), by Chiesi Farmaceutici S.p.a. (H.S.), Italy, and Oscar II:s Jubileumsfond (T.C.).
Surfactant therapy of the respiratory distress syndrome has saved the life of many preterm infants (1). However, the incidence of intraventricular hemorrhage has generally not been reduced by surfactant rescue treatment $(2,3)$; this is contrary to expectations, inasmuch as this new therapy has been shown to significantly reduce the rate of pneumothoraces $(2,3)$. The occurrences of pneumothorax and intracranial hemorrhage are highly correlated $(4,5)$. Cowan et al. (6) observed considerable changes in arterial BP shortly after surfactant administration parallel to changes in cerebral blood flow velocities in preterm infants. Such fluctuations have also been reported by others $(7,8)$; they may increase the risk of intraventricular hemorrhage $(6,9)$.

To avoid adverse effects to the cerebral circulation, Jorch $e t$ al. (7) and Cowan et al. (6) suggested alternatives to the bolus instillation of surfactant. However, this latter technique is considered the only instillation procedure that facilitates a homogeneous pulmonary surfactant distribution as a prerequisite for optimal efficacy $(10-12)$.

The aim of this animal study was to evaluate slow tracheal infusion of surfactant as a possible alternative to bolus administration. Therefore, pulmonary distribution of a labeled natural surfactant preparation and its effects on pulmonary gas exchange and BP were compared after standard bolus administration and after slow tracheal infusion.

\section{MATERIALS AND METHODS}

Surfactant preparations and labeling techniques. A natural porcine surfactant preparation, CS (13) was used. The evaporated, dry material was frozen and kept at $-20^{\circ} \mathrm{C}$ before final suspension in saline. For radioactive labeling, ${ }^{14} \mathrm{C}$-DPPC (L-3phosphatidyl[ $\mathrm{N}$-methyl- $\left.{ }^{14} \mathrm{C}\right]$ choline-1,2-dipalmitoyl) was used (Amersham Nederland BV, 's-Hertogenbosch, The Netherlands). After dissolving the dry CS in chloroform/methanol 2:1 (vol/ vol), $1.5 \mu \mathrm{Ci}$ of ${ }^{14} \mathrm{C}$-DPPC $(55.5 \mathrm{kBq})$ was added per $\mathrm{g}$. The mixture was evaporated to dryness under nitrogen and suspended in normal saline to a concentration of $50 \mathrm{mg} / \mathrm{mL}$. Each animal received $200 \mathrm{mg} / \mathrm{kg}$ body weight.

To evaluate a nonradioactive labeling technique for surfactant distribution studies, RMS were also added to the surfactant preparation. They were obtained in a suspension of $3 \times 10^{6}$ microspheres $/ \mathrm{mL}$ aqueous solution (Triton Technology, Inc., San Diego, CA), with a diameter of $15.5 \pm 0.2 \mu$ m (mean \pm SD). The specific weight is $1.09 \mathrm{~g} / \mathrm{mL}$ (14); in a CS suspension of 50 
$\mathrm{mg} / \mathrm{mL}$ in normal saline, the sedimentation rate is less than 0.5 $\mathrm{mm} / \mathrm{h}$, whereas in a suspension of $25 \mathrm{mg} / \mathrm{mL}$, it is approximately $10 \mathrm{~mm} / \mathrm{h}$. A total of $1.5 \times 10^{5} \mathrm{RMS}$ were added to each $\mathrm{mL}$ of the surfactant suspension. After radioactive labeling and addition of microspheres, the property of the preparation to improve gas exchange in an animal model of surfactant deficiency (15) was unchanged (data not shown).

Animal studies. All animal experiments were performed after approval of the Animal Care and Use Committee of the Erasmus University, Rotterdam.

Instillation and distribution studies. In 13 adult male New Zealand White rabbits (Harlan/CPB, Zeist, The Netherlands) with a body weight of $2.5 \pm 0.2 \mathrm{~kg}$ (mean $\pm \mathrm{SD}$ ), anaesthesia was induced by i.v. sodium pentobarbital $(30 \mathrm{mg} / \mathrm{kg}$ body weight $)$ and maintained by hourly i.v. injections of $10 \mathrm{mg} / \mathrm{kg}$. The animals were positioned on their back and not moved during the experiment. An uncuffed tracheal tube (inner diameter 4.0 $\mathrm{mm}$ ) with monitoring lumen (Mallinckrodt Critical Care, Glens Falls, NY) was inserted by tracheostomy, and the left femoral artery was cannulated for blood gas sampling and BP monitoring. The rabbits were paralyzed (pancuronium bromide $0.1 \mathrm{mg} / \mathrm{kg}$ body weight intramuscularly) and artificially ventilated (Servo Ventilator 900 C. Siemens-Elema. Solna, Sweden) using the pressure-controlled mode, with a constant fraction of inspired oxygen of 1.0 , a frequency of $30 / \mathrm{min}$, an inspiration:expiration ratio of $1: 2$, and a PEEP of $2 \mathrm{~cm} \mathrm{H}_{2} \mathrm{O}(0.2 \mathrm{kPa})$. The PIP was initially varied from $8-12 \mathrm{~cm} \mathrm{H}_{2} \mathrm{O}(0.8-1.2 \mathrm{kPa})$ to keep the expiratory tidal volume (measured by pneumotachography) between 9 and $12 \mathrm{~mL} / \mathrm{kg}$ body weight. Thus, $\mathrm{PaCO}_{2}$ values of $4.6-$ $6.6 \mathrm{kPa}$ were maintained.

Surfactant deficiency was induced by lung lavages as described previously $(16,17)$. At the beginning of the lavage procedure, PEEP was increased to $6 \mathrm{~cm} \mathrm{H} \mathrm{H}_{2} \mathrm{O}(0.6 \mathrm{kPa})$, whereas PIP was increased according to the expiratory tidal volume. Lavages using $30 \mathrm{~mL} / \mathrm{kg}$ body weight of saline $\left(37^{\circ} \mathrm{C}\right)$ were repeated three to six times until the $\mathrm{PaO}_{2}$ was less than $10.5 \mathrm{kPa}$ and did not increase again during the following $10 \mathrm{~min}$.

Surfactant administration. The rabbits were assigned to two groups: eight animals received CS by bolus instillation, and five animals by slow tracheal infusion. For bolus administration, a Charriere 5 feeding tube was inserted through the lumen of the tracheal tube and advanced to a point about $1 \mathrm{~cm}$ below the tube's tip (18). Surfactant was instilled within approximately 10 $\mathrm{s}$, followed by an injection of $12-14 \mathrm{~mL} / \mathrm{kg}$ of air. Then the endotracheal tube was reconnected to the ventilator tubes. Tracheal infusion of surfactant was done during approximately 45 min via the monitoring lumen within the wall of the tracheal tube. With the latter instillation procedure, no air was injected and artificial ventilation was not interrupted because the tracheal tube was not disconnected from the ventilatory tubes. After the beginning of surfactant instillation. PIP was adjusted whenever necessary to keep tidal volume and $\mathrm{PaCO}_{2}$ in the same range as before lavage. No other changes in ventilatory parameters were made.

In two rabbits treated with a CS bolus and two rabbits treated with CS tracheal infusion, the preparation was labeled with both ${ }^{14} \mathrm{C}$-DPPC and RMS. All further distribution studies were done by RMS labeling only.

At $68 \mathrm{~min}$ (mean, SEM $1.7 \mathrm{~min}$ ) after CS bolus instillation or 73 min (mean, SEM $3.3 \mathrm{~min}$; difference statistically not significant) after the start of CS infusion, four rabbits of each group were killed by an overdose of pentobarbital and their lungs processed for evaluation of the pulmonary surfactant distribution.

Lung processing. Before the thoracic cage was opened, the lungs were inflated with a continuous distending pressure of 15 $\mathrm{cm} \mathrm{H}_{2} \mathrm{O}(1.5 \mathrm{kPa})$; as soon as this pressure was achieved, the tracheal tube was clamped. Lungs and heart were removed en bloc and immediately frozen by immersion in fluid nitrogen. After $4 \mathrm{~h}$ at $-20^{\circ} \mathrm{C}$, the lungs were dissected into $50-70$ pieces.
For this purpose, each lung was cut into five horizontal slices that were divided into a front, medial, and rear piece. Each of these pieces were, depending on their size, subdivided into two or three parts. We tried to avoid weights below $50 \mathrm{mg}$ or above $1000 \mathrm{mg}$. The weights before thawing and the position of each piece were noted; the total lung weight of each rabbit was calculated from these data. Each lung specimen was placed in a glass test tube (Duran, Schott Glaswerke, Mainz, Germany). For tissue digestion, $4 \mathrm{M} \mathrm{KOH}$ containing $2 \%$ Tween 80 were added in a ratio of $10: 1$ (vol/wt). After capping the tubes with a Teflonsealed screw cap, the samples were placed in a water-bath shaker for $4 \mathrm{~h}$ at $72^{\circ} \mathrm{C}$.

Measurement of radioactivity. In those animals that received radioactively labeled $\mathrm{CS}, 200 \mu \mathrm{L}$ of each tissue solution were mixed with $1 \mathrm{~mL}$ of water and $10 \mathrm{~mL}$ of Insta-Gel (Packard Instrument Co., Downers Grove, IL) for liquid scintillation counting (Tri Carb Liquid Scintillation Analyzer, model 2500 TR, Packard Instrument Co.) Because of transient luminescence, the samples were not counted before $72 \mathrm{~h}$ after preparation. An external standard was used to control the quenching effect.

Measurement of number of microspheres. The RMS in each lung piece were recovered by vacuum filtration of the tissue solution through a membrane (Nuclepore polyester filter, pore size $8 \mu \mathrm{m}, 25 \mathrm{~mm}$ diameter; Costar Europe Ltd., Badhoevedorp, The Netherlands) (14). To avoid loss of RMS, the test tube was rinsed with $2 \%$ Tween 80 in an aqueous solution, which was then also filtered. The membrane was placed into an Eppendorf test tube and allowed to dry overnight. After addition of $600 \mu \mathrm{L}$ of dimethylformamide (DMF, Sigma Chemie GmbH, München, Germany) to remove the red dye from the microspheres, the tube was closed and shaken. Five hundred $\mu \mathrm{L}$ of the red fluid were transferred into a glass microcuvette and the absorbance was measured at $533 \mathrm{~nm}$ (PU 8720 UV/VIS scanning spectrophotometer, Philips, Eindhoven. The Netherlands). For the calibration curve, duplicate samples of $4500,15000,30000$, and 45000 RMS were treated and analyzed as described above. The values obtained did not differ whether $4 \mathrm{M} \mathrm{KOH}$ or water was used for dilution, whether the suspension was treated in the water-bath shaker, or whether the dye solution was centrifuged before photometry (data not shown).

Data evaluation. Radioactivity (cpm) and number of RMS per lung piece were compared in four animals. The distribution of surfactant was calculated from the number of RMS and $\mathrm{cpm} / \mathrm{g}$ of each lung piece. From the total number of RMS or cpm recovered from each animal, and the total lung weight of each animal, the expected values per $g$ lung weight were calculated. Values of individual pieces were divided by these expected values. In this way, normalized distribution values were obtained: they are presented as histograms with interval widths of $10 \%$ about the expected value of $1.0(10)$.

Recoveries were calculated for each animal by summarizing the number of RMS and cpm in all lung pieces and trachea samples and dividing these results by the number/radioactivity in the surfactant suspension delivered to the animal.

Statistical analysis. The Mann-Whitney U test was applied to evaluate differences between continuous variables in the two groups. For comparisons of repeated measurements, two-factor analysis of variance was performed. These procedures and Pearson's correlation coefficient were calculated with the SPSS/PC+ statistical package (SPSS Inc., Chicago, IL). Statistical significance was defined as $p<0.05$.

\section{RESULTS}

Pulmonary distribution of radioactivity and RMS was compared in the four rabbits ventilated for about $70 \mathrm{~min}$ after instillation of double-labeled CS. The lungs were cut into a total of 258 pieces. The weights of these pieces varied from 49 to 1070 $\mathrm{mg}$ with a mean of $436 \mathrm{mg}$ (SD, $227 \mathrm{mg}$ ).

The correlation coefficient $(r)$ between the number of RMS 
and the radioactivity per $\mathrm{g}$ of each lung piece was $0.92\left(r^{2}=\right.$ 0.85 ), as was the correlation coefficient between the normalized distribution values (Fig. 1). The nonnormalized correlation between the number of RMS to cpm per lung piece was 0.96 for the 258 pieces. The recovery for RMS $70 \mathrm{~min}$ after surfactant bolus instillation was $80 \pm 9.0 \%(n=4)$; after infusion, it was $85 \pm 5.5 \%(n=4)$. This difference was not significant.

After $\mathrm{CS}$ bolus instillation, $\mathrm{PaO}_{2}$ values increased rapidly within the first minutes and then slowly during the following hour (Fig. 2A). PIP (Fig. $2 B$ ) and mean airway pressure (data not shown) remained unchanged. Systolic (Fig. $2 C$ ) and mean arterial BP (data not shown) dropped during the first minutes after surfactant administration. In two animals, PEEP was reduced to $2 \mathrm{~cm} \mathrm{H}_{2} \mathrm{O}$ for 2 to $3 \mathrm{~min}$ during arterial hypotension. BP immediately returned to values similar to those measured before surfactant replacement. The normalized distribution of surfactant approximately $70 \mathrm{~min}(68 \mathrm{~min}, \mathrm{SEM} 1.7 \mathrm{~min})$ after bolus instillation was reasonably homogeneous (Fig. $3 A$ ). The proportion of lung pieces receiving $\leq 0.15$ of the expected number of RMS per lung weight was very low (mean $2.6 \%$, SEM $2.2 \%$; $n=4)$.

Intratracheal infusion of CS was done during $43.6 \mathrm{~min}$ (SEM $2.1 \mathrm{~min}$ ). Figure 2 shows that PIP had to be slightly increased to keep $\mathrm{PaCO}_{2}$ values in the normal range, BP remained stable, and $\mathrm{PaO}_{2}$ values did not change during the observation period and did not show a tendency toward increase even at $60 \mathrm{~min}$ after the onset of infusion. The distribution histogram (Fig. 3B) of four rabbits killed after approximately $70 \mathrm{~min}$ (mean $73 \mathrm{~min}$, SEM $3.3 \mathrm{~min}$ ) shows a completely inhomogeneous distribution with an extremely high proportion of values $\leq 0.15$ of the expected value (mean $47 \%$, SEM $8.1 \% ; n=4$ ). This proportion was significantly different from that observed after bolus instillation $(p<0.05)$.

\section{DISCUSSION}

Radioactive labeling of surfactant to study its pulmonary distribution is a well-accepted method. In animal experiments, the distribution of exogenous surfactant has been investigated by adding ${ }^{3} \mathrm{H}$ - or ${ }^{14} \mathrm{C}$-labeled DPPC $(10,11,12,19)$, radioactive microspheres (20), or other radioactive particles (21) to the surfactant preparation. However, any method that uses radioactive isotopes has some disadvantages: the laboratory must be equipped and licensed to handle radioactive material; personnel must be specially trained and supervised; precautions have to be observed to avoid contamination of persons and equipment, and radioactive waste requires separate storage space and disposal.

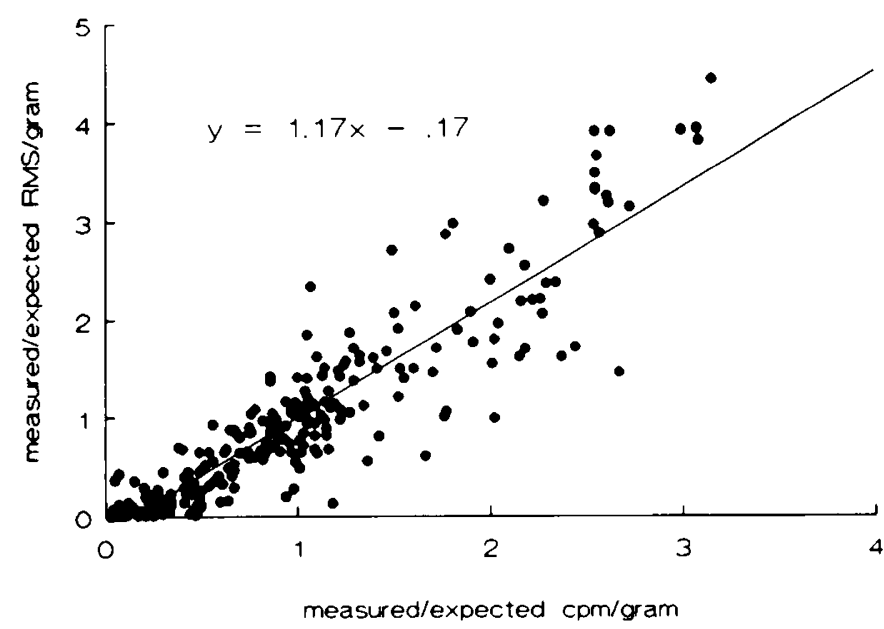

Fig. 1. Correlation of normalized values (measured/expected) of RMS to radioactivity (cpm) in 258 lung pieces of four rabbits ventilated for $70 \mathrm{~min}$ after the start of surfactant instillation. Correlation coefficient is $0.92 ; p<0.0001$.
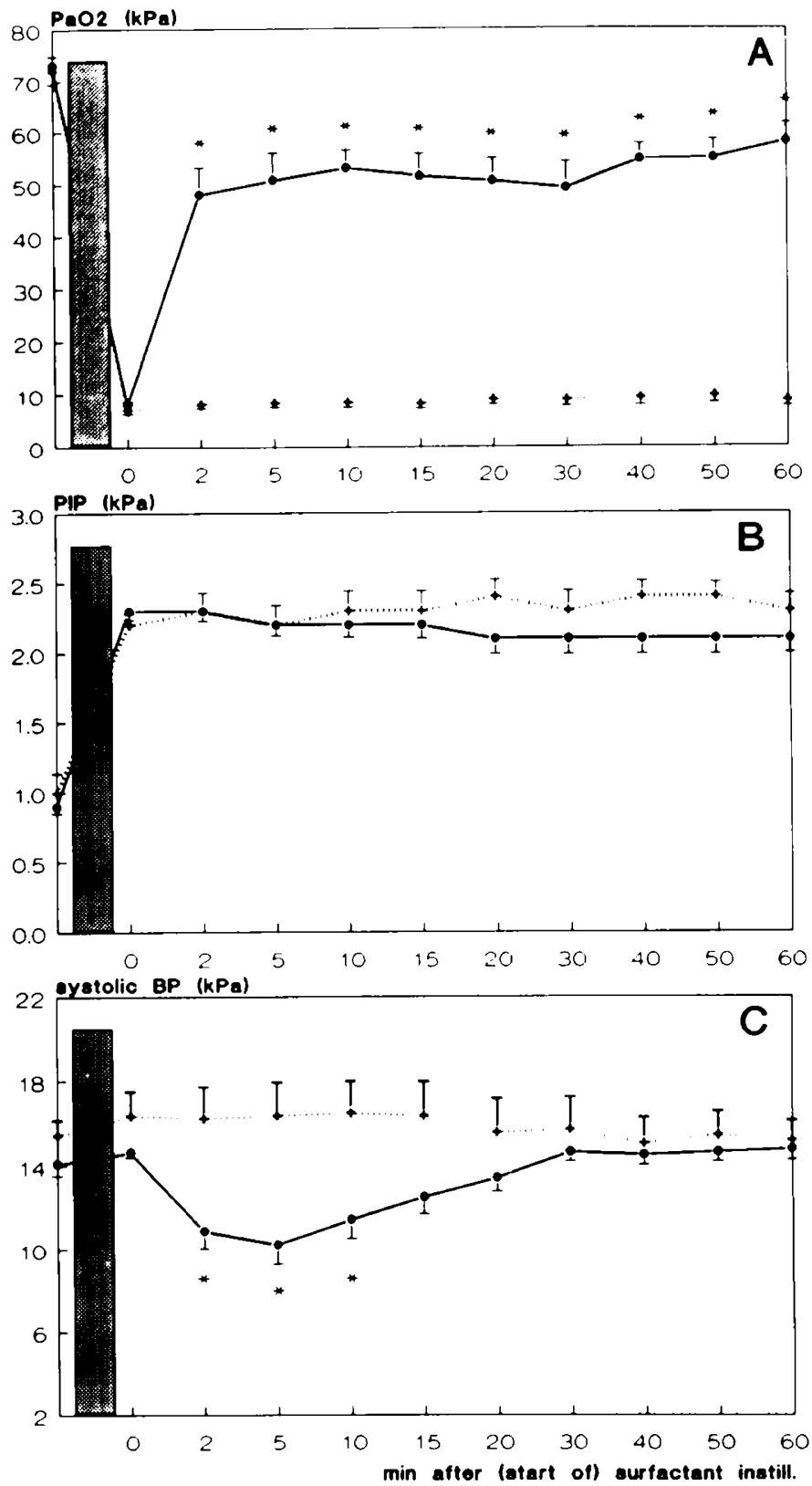

Fig. 2. $\mathrm{PaO}_{2}(A)$. PIP $(B)$, and systolic $\mathrm{BP}\left(C^{\prime}\right)$ in eight rabbits before and after CS bolus instillation (- - ) and in four rabbits after CS slow tracheal infusion (..+..). Time axis is discontinuous. Shaded column represents saline lung lavages. Values are mean \pm SEM. There were no significant differences between groups before and after lung lavage. In $A$. the differences between the curves are statistically significant by twofactor analysis of variance $(p<0.01)$ during the period 2 to $60 \mathrm{~min}$ after the start of surfactant instillation (*). In $C$, values for the infusion group are significantly different from the bolus values $(p<0.01$, two-factor analysis of variance) during the period 2 to $15 \mathrm{~min}$ after the start of surfactant instillation $\left({ }^{*}\right)$.

For these reasons, substitution of radioactive methods by other techniques seems to be desirable. Using RMS, we believe to have found a nonradioactive method that is suitable for studies of the pulmonary distribution of exogenous surfactant in animal experiments. Colored microspheres have been used to replace radioactive microspheres in the measurement of regional myocardial blood flow $(14,22)$. Radioactive microspheres added to a surfactant preparation show a similar distribution pattern in the lung as radioactive DPPC incorporated in the surfactant (20). The microspheres used in this study have the same size as the radioactive microspheres used by others (20). Their density (1.09 

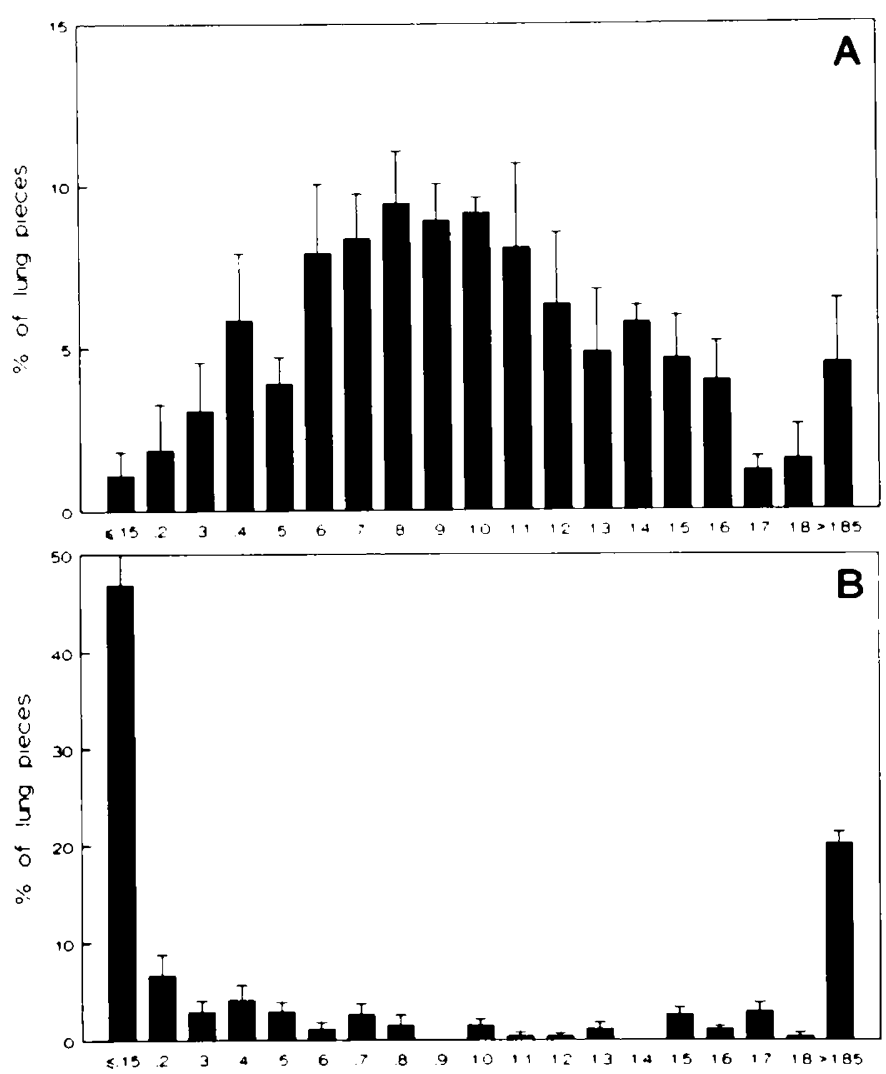

Fig. 3. Normalized distribution of RMS after bolus instillation (.4) and after slow tracheal infusion $(B)$, expressed as the percentage of pieces of lung in each $10 \%$ distribution interval. Each figure represents the results from four animals (263 lung pieces in $A$ and 268 pieces in $B$; mean + SEM)

$\mathrm{g} / \mathrm{mL}$ ) is closer to that of physiologic fluids [plasma, blood: 1.02 to $1.05 \mathrm{~g} / \mathrm{mL},(23)]$ than is the density of radioactive microspheres [1.3 g/mL (14)].

The results of this study show that use of RMS to determine the distribution of exogenous surfactant yields data similar to that with the use of ${ }^{14} \mathrm{C}$-DPPC. This is surprising because one expects that particles of $15-\mu \mathrm{m}$ diameter will rapidly separate from a material that easily spreads to form a thin layer on airwater interfaces. However, Schürch $e t$ al. (24) (in a study using latex particles of $6-\mu \mathrm{m}$ diameter or less) recently reported that small particles are completely coated with surfactant and submerged in the aqueous subphase of the alveolar lining layer. In other words, these very small particles remain in close contact with the surfactant. We assume that this mechanism also applies to microspheres delivered with exogenous surfactant. Microspheres could in this way be ideal vehicles for agents that are intended to act in the aqueous subphase or on pulmonary epithelial cells.

As reported in preterm infants (6), surfactant bolus administration can cause a sudden decrease in BP. A similar effect was observed in this animal study (Fig. $2 C$ ). The reason for these fluctuations is unclear; our study was not designed to investigate this problem. The anecdotal observation in two rabbits suggests a relation between the level of PEEP and the BP after surfactant treatment that should be clarified by further investigations.

Such decreases in BP were completely avoided with surfactant infusion via the monitoring lumen of the tracheal tube. With the instillation by slow infusion, we not only hoped to avoid BP decreases and fluctuations of the $\mathrm{PCO}_{2}(25)$, but also expected to obtain a slow onset of the surfactant action so that it would be possible to titrate the surfactant dose to the desired effect. For this reason, a relatively long infusion time was chosen.

However, there were no beneficial effects on oxygenation with this method of surfactant instillation compared with bolus instillation. The reason for this somewhat disappointing result seems to be the extremely uneven distribution produced by surfactant infusion, so that in many parts of the lung the surfactant concentration may be below its critical concentration (26). Apparently, by slow infusion of CS only a minor part of the total lung is supplemented by surfactant, so this technique is far from optimal for clinical practice.

Jobe et al. (10) showed that the distribution of exogenous surfactant is homogeneous if delivered immediately after birth but "very nonhomogeneous" if supplied after the onset of mechanical ventilation. Gilliard et al. (12) demonstrated that the larger the volume in which a certain amount of surfactant is delivered, the more homogeneous is its distribution. Bambang Oetomo et al. (20) and van der Bleek et al. (27) confirmed these observations. They found a nonuniform distribution with volumes between 2.4 and $8 \mathrm{~mL} / \mathrm{kg}$ body weight. In the present study, the distribution was reasonably although not completely homogeneous, with a surfactant volume of $4 \mathrm{~mL} / \mathrm{kg}$. For a comparison between these results, methodologic differences should be considered. van der Bleek $e t$ al. (27) used the "monitoring lumen" as a route to the lower trachea; the amount of surfactant was lower: the time for instillation was longer; the pressure during instillation was limited; they did not flush the airways with air; their mode of artificial ventilation was volume control, at a frequency of $60 / \mathrm{min}$; and the animals were killed $15 \mathrm{~min}$ after surfactant instillation. Some of these differing factors may have an impact on the distribution of the instilled surfactant: however, to our knowledge, they have not been investigated in detail up to now.

Heldt et al. (28) describe a normal distribution of exogenous surfactant instilled into preterm rabbits as a bolus followed by repeated injections of air either at birth or after $15 \mathrm{~min}$ of ventilation. They cut the lungs of each animal into only 16 pieces. It seems likely that the number of pieces per examined lung, i.e. the resolving power, influences the results concerning the uniformity of a distribution: the closer the view, the coarser the pattern (29).

With the marked differences in the uniformity of distribution after slow infusion compared with bolus instillation observed in the present study, we speculate that minor differences in the bolus instillation technique may lead to differences in the pulmonary distribution and in the properties of exogenous surfactant. This possibility should be considered when the standard methods of surfactant instillation used in the controlled surfactant trials of the 1980s (1) and shown to be efficacious are modified.

Conclusions. The use of RMS in animal studies of surfactant distribution is a suitable substitute for radioactive labels. It allows reliable determination of the pulmonary distribution of exogenous surfactant.

The mode of instillation influences the pulmonary distribution of an exogenous surfactant preparation. The distribution of surfactant is closely related to its effects on pulmonary gas exchange.

We speculate that inadequate techniques of surfactant instillation may add to the causes of "poor response" (30) after surfactant replacement.

Acknowledgments. The authors thank Dr. A. Jobe, Dr. B. Robertson, and Th. Ehring for valuable suggestions; Dr. W. Hopfenmüller for statistical advice; Laraine Visser-Isles for English language editing; and A. Kok for outstanding technical assistance. We are grateful to Elin Arvesen, Brigitta Jonsson, and Gunhild Nilsson for preparing the surfactant.

\section{REFERENCES}

1. Merritt TA. Hallman M. Spragg R. Heldt GP. Gilliard N 1989 Exogenous surfactant treatments for neonatal respiratory distress syndrome and their potential role in the adult respiratory distress syndrome. Drugs 38:591-611 
2. Morley CJ 1991 Surfactant treatment for premature babies: a review of clinical trials. Arch Dis Child 66:445-450

3. Hennes HM, Lee MB, Rimm AA, Shapiro DL 1991 Surfactant replacement therapy in respiratory distress syndrome. Meta-analysis of clinical trials of single-dose surfactant extracts. Am J Dis Child 145:102-104

4. Dykes FD, Lazzara A, Ahmann P, Blumenstein B, Schwartz J, Brann AW 1980 Intraventricular hemorrhage: a prospective evaluation of etiopathogenesis. Pediatrics 66:42-49

5. Mehrabani D, Gowen Jr CW, Kopelman AE 1991 Association of pneumothorax and hypotension with intraventricular haemorrhage. Arch Dis Child 66:48-51

6. Cowan F, Whitelaw A, Wertheim D, Silverman M 1991 Cerebral blood flow velocity changes after rapid administration of surfactant. Arch Dis Child 66:1105-1109

7. Jorch G, Rabe H. Garbe M. Michel E. Gortner L 1989 Acute and protracted effects of intratracheal surfactant application on internal carotid blood flow velocity, blood pressure and carbon dioxide tension in very low birth weight infants. Eur J Pediatr 148:770-773

8. van de Bor M. Ma EJ. Walther FJ 1991 Cerebral blood flow velocity after surfactant instillation in preterm infants. J Pediatr 118:285-287

9. Lou HC, Lassen NA, Friis-Hansen B 1979 Impaired autoregulation of cerebral blood flow in the distressed newborn infant. J Pediatr 94:118-121

10. Jobe A, Ikegami M, Jacobs H, Jones S 1984 Surfactant and pulmonary blood flow distributions following treatment of premature lambs with natural surfactant. J Clin Invest 73:848-856

11. Walther FJ, Kuipers IM, Gidding CEM, Willebrand D, Buchholtz RTF, Bevers EM 1987 A comparison of high-frequency oscillation superimposed onto back-up mechanical ventilation and conventional mechanical ventilation on the distribution of exogenous surfactant in premature lambs. Pediatr Res 22:725-729

12. Gilliard N, Richman PM. Merritt TA. Spragg RG 1990 Effect of volume and dose on the pulmonary distribution of exogenous surfactant to normal rabbits or to rabbits with oleic acid lung injury. Am Rev Respir Dis 141:743747

13. Robertson B. Curstedt T. Johansson J, Jörnvall H, Kobayashi T 1990 Structural and functional characterization of porcine surfactant isolated by liquid-gel chromatography. Prog Respir Res 25:237-246

14. Kowallik P, Schulz R, Guth BD, Schade A. Pafthausen W, Gross R. Heusch G 1991 Measurement of regional myocardial blood flow with multiple colored microspheres. Circulation 83:974-982

15. Lachmann B. Berggren P. Curstedt T. Grossmann G, Robertson B 1984 Surfactant replacement in experimental respiratory distress syndrome (RDS) induced by lung lavage. Prog Respir Res 28:251-256

16. Lachmann B, Robertson B. Vogel J 1980 In vivo lung lavage as an experimental model of the respiratory distress syndrome. Acta Anaesthesiol Scand 24:231236

17. Lachmann B, Jonson B, Lindroth M, Robertson B 198 2 Modes of artificial ventilation in severe respiratory distress syndrome. Crit Care Med 10:724732

18. Collaborative European Multicenter Study Group 1988 Surfactant replacement therapy for severe neonatal respiratory distress syndrome: an international randomized clinical trial. Pediatrics 82:683-691

19. Ikegami M, Jobe A. Jacobs H. Jones SJ 1981 Sequential treatments of premature lambs with artificial surfactant and natural surfactant. J Clin Invest 68:491-496

20. Bambang Oetomo S, Lewis J, Ikegami M, Jobe AH 1990 Surfactant treatments alter endogenous surfactant metabolism in rabbit lungs. J Appl Physiol $68: 1590-1596$

21. Brain JD, Knudson DE, Sorokin SP, Davis MA 1976 Pulmonary distribution of particles given by intratracheal instillation or by aerosol inhalation. Environ Res 11:13-33

22. Hale SL, Alker KJ, Kloner RA 1988 Evaluation of nonradioactive, colored microspheres for measurement of regional myocardial blood flow in dogs Circulation 78:428-434

23. Documenta Geigy 1972 Tables Scientifiques, 7th Ed. Ciba-Geigy SA. Bale Switzerland, p 568

24. Schürch S. Gehr P. Im Hof V. Geiser M. Green F 1990 Surfactant displaces particles toward the epithelium in airways and alveoli. Respir Physiol 80:1732

25. Skov L. Hellström-Westas L, Jacobsen T. Greisen G. Svenningsen NW 1992 Acute changes in cerebral oxygenation and cerebral blood volume in preterm infants during surfactant treatment. Neuropediatrics 23:126-130

26. Kobayashi T, Shido A. Nitta K. Inui K. Ganzuka M. Robertson B 1990 The critical concentration of surfactant in fetal lung liquid at birth. Respir Physio 80:181-192

27. van der Bleek J. Plötz FB, van Overbeek FM. Heikamp A, Beekhuis $H$ Wildevuur ChRH, Okken A. Bambang Oetomo S 1993 Distribution of exogenous surfactant in rabbits with severe respiratory failure: the effect of volume. Pediatr Res 34:154-158

28. Heldt GP. Merritt TA. Golembeski D. Gilliard N, Bloor C, Spragg R 1992 Distribution of surfactant. lung compliance, and aeration of preterm rabbit lungs after surfactant therapy and conventional and high-frequency oscillatory ventilation. Pediatr Res 31:270-275

29. Mandelbrot BB 1967 How long is the coast of Britain? Statistical self-similarity and fractional dimension. Science 156:636-638

30. Segerer H, Stevens P. Schadow B. Maier R, Kattner E. Schwarz H, Cursted T. Robertson B. Obladen M 1991 Surfactant substitution in ventilated very low birth weight infants: factors related to response types. Pediatr Res 30:591-596 